\title{
A Method for Preparing Environmental Social Impact Assessment (ESIA) of Crude Oil and Gas Pipelines
}

\author{
Huseyin Murat Cekirge ${ }^{1}$, Omar K. M. Ouda ${ }^{2}$, Ammar Elhassan $^{3}$ \\ ${ }^{1}$ Department of Mechanical Engineering, Prince Mohammad Bin Fahd University, Al Khobar, KSA \\ ${ }^{2}$ Department of Civil Engineering, Prince Mohammad Bin Fahd University, Al Khobar, KSA \\ ${ }^{3}$ Department of Information Technology, Prince Mohammad Bin Fahd University, Al Khobar, KSA
}

Email address:

hmcekirge@usa.net (H. M. Cekirge),oouda@pmu.edu.sa (O. K. M. Ouda), aelhassan@pmu.edu.sa (A. Elhassan)

\section{To cite this article:}

Huseyin Murat Cekirge, Omar K. M. Ouda, Ammar Elhassan. A Method for Preparing Environmental Social Impact Assessment (ESIA) of Crude Oil and Gas Pipelines. International Journal of Environmental Monitoring and Analysis. Vol. 3, No. 3, 2015 , pp. 154-161.

doi: 10.11648/j.ijema.20150303.17

\begin{abstract}
The principles of preparing ESIA for crude oil and gas pipelines are introduced and various stages of the report development are presented. The paper is a guideline for preparing an ESIA without any omitted measures of an oil or gas pipeline. These guidelines are presented in detail and will be handbook of presenting and introducing mitigation measures. It is aimed at presenting non quantitative ESIA and however at detailed flow of ESIA preparation.
\end{abstract}

Keywords: ESIA, Environmental and Social Impact Assessment, Mitigation, Livelihood, Landscape, Preparation of ESIA, Structure of ESIA

\section{Introduction}

Energy source security and reliability, particularly during times of social or political change is a strategic requirement. Oil and gas pipeline security is one of the highest value assets in this area and hence, new crude oil or gas pipelines need to be constructed in various locations. One of the major challenges in constructing these pipelines is the environmental impact, and although crude oil and gas pipeline construction causes similar impact on the environment there are differences nonetheless, not least due to the physical differences between the two commodities. Oil spills, for example, are a major risk associated with crude oil pipelines whereas toxic gas leaks, explosions and fires are the main concerns associated with gas pipelines.

Any pipeline project plan needs to be subjected to an Environmental and Social Impact Assessment (ESIA) [1], [2], [3], [4], [5], [6], [7], [8], [9] and [10], which needs to be in conformance with international practices. ESIA aims to ensure that all potential impacts of the pipeline project on the physical, biological and human environment are analyzed, assessed and, where necessary, managed. Carrying out the many studies required for a comprehensive ESIA and reporting of the ESIA findings are an integral part of the ESIA study.
Proposals for new pipelines need to be accompanied with state of the art technology for monitoring operations, including control and leak detection systems, to immediately identify operational problems and to minimize the potential for environmental incidents. Specific design details at each location along the route, such as coating systems, wall thickness, cathodic protection, as well as other aspects need to be determined as part of any detailed engineering phase of the project. Special designs will be implemented where appropriate, such as at river and fault crossings and in areas of potential land instability, thereby ensuring that all prudent and internationally recognized technological measures are implemented at all sensitive locations to protect the pipeline and the surrounding environment. The ESIA must cover Above Ground Installations (AGIs), which are a custody metering, pump stations a pressure reduction station / pigging facility, to reduce pipeline pressure; block valve stations and facilities for monitoring and maintaining the internal integrity of the pipeline and at end maybe a marine terminal.

It is avoided quantitative description of ESIA; however a comprehensive detailed flow and preparation structure of ESIA are presented throughout the paper. Quantitative analyses are not considered in the content of this study, since the preparation and flow of ESIA are the main subject of the paper. 


\section{Pipeline Axis Assessment}

Potential pipeline routes are subjected to a two-step process to identify good routes.

i. The first step consist of selecting 'Potential Route Corridors' within a width of $100 \mathrm{~km}$ to the level of detail permitted by maps with scales of $1: 2,000,000$ or $1: 500,000$.

ii. The second step, a semi-quantitative Environmental Risk Assessment (ERA), evaluates the relative risk of oil spills associated with bulk transportation by pipeline and shipping between loading and unloading terminals.

A Geographic Information System (GIS) is used to spatially represent and process data during the identification of potential route corridors, loading and unloading terminals. For these locations of environmental features should be also plotted, Table 1, including:

Table 1. The protected areas.

\begin{tabular}{ll}
\hline protected areas & Wetlands \\
\hline Forests & Geomorphological landforms \\
zones of seismic risk & zones prone to flash-flooding \\
geo-technical classifications & cultural heritage sites \\
\hline
\end{tabular}

During the Basic Engineering (BE) phase, the previously established 'Corridor of Interest' is subject to confirmation and refinement, in order to consolidate the corridor for the selection of environmental baseline data and subsequent narrowing to the $500 \mathrm{~m}$ wide 'Preferred Route Corridor'. In addition to the overall verification of the initial 'Corridor of Interest' discussed above, the primary objective of the $\mathrm{BE}$ phase is the narrowing of the $10 \mathrm{~km}$ wide corridor to a 'Preferred Route Corridor' of 500 m width.

The route narrowing process is carried out in an iterative process with inputs from various disciplines. The final result, the 'Preferred Route Corridor' is established inside the investigated 'Corridor of Interest'. The following main criteria are considered during this route narrowing process: Topography (e.g. elevations, slopes etc.)

- Social sensitivities (e.g. avoiding settlements, schools, cemeteries)

- Ecological considerations (e.g. protected or sensitive areas)

- $\quad$ Land slide and karst areas

- Faults and areas of potential liquefaction

- Archaeological sites

- Hydrology

- Meteorology

- Archaeological sites

- Third Party and Authority Requirements (e.g. infrastructure planning and development)

- Technical considerations (e.g. constructability).

Desktop exercises are undertaken and relevant constraints are laid onto constraint maps (using GIS) in order to help establish an inspection centerline, which was then verified in the field by relevant discipline experts. This is followed by the specification process of the route of corridor (100 meters), construction corridor and pipeline centerline axis.

\section{Stages of the ESIA Process}

This ESIA takes into account full understanding of agreements and the requirements therein and is therefore compliant with the applicable provisions of the country where the pipeline will be constructed.

This ESIA Report describes the impacts that the proposed pipeline project will have upon the existing environmental and social conditions along the pipeline corridor, and how these impacts will be mitigated. Environmental and social assessments will be incorporated into each previous stage of the project design process, thereby significantly influencing how the project is developed. The early integration of environmental and social considerations in the planning of the proposed pipeline ensures that many potential impacts of the project will not be realized as steps are taken to avoid or design out the impact potential.

It is pertinent to note that the high level of interface between the basic/detailed engineering and ESIA program has led to the situation where this ESIA report now describes and assesses a near defined route rather than (as is usually the case in ESIA) a broad route corridor. While this route is still subject to ongoing design and assessment (and hence route changes) there is significantly more certainty concerning the route and the likely level of the associated impacts than is normal when disclosing pipeline ESIA reports for public review.

The overall objective of the ESIA process is to ensure that all potential adverse environmental or social effects arising from the pipeline construction, operation and decommissioning are identified, and where feasible eliminated or minimized through implementation of appropriate design measures.

Where it has not been possible to eliminate or minimize impact through design, the ESIA process identifies those environmental and social mitigation measures that have been developed in conjunction with the engineering team and stakeholders; those measures will, then, be implemented by Designated Operators.

Where residual impacts or significant uncertainties are a factor, additional mitigation measures are formulated to minimize their effect, supported, where necessary, by specification of additional studies and by more extensive monitoring.

Stages in the ESIA Process are, Figure 1:

i. Defining the Project,

ii. Scoping,

iii. Consultation,

iv. Baseline Data Collection,

v. Assessment and Disclosure,

vi. To provide information necessary to facilitate a full understanding of the environmental and social impacts of the proposed project and the associated mitigation measures that will be implemented,

vii. To encourage discussion and invite comments on the proposed mitigation measures. Comments received during the disclosure process will be reviewed and 
where necessary incorporated into this ESIA report.
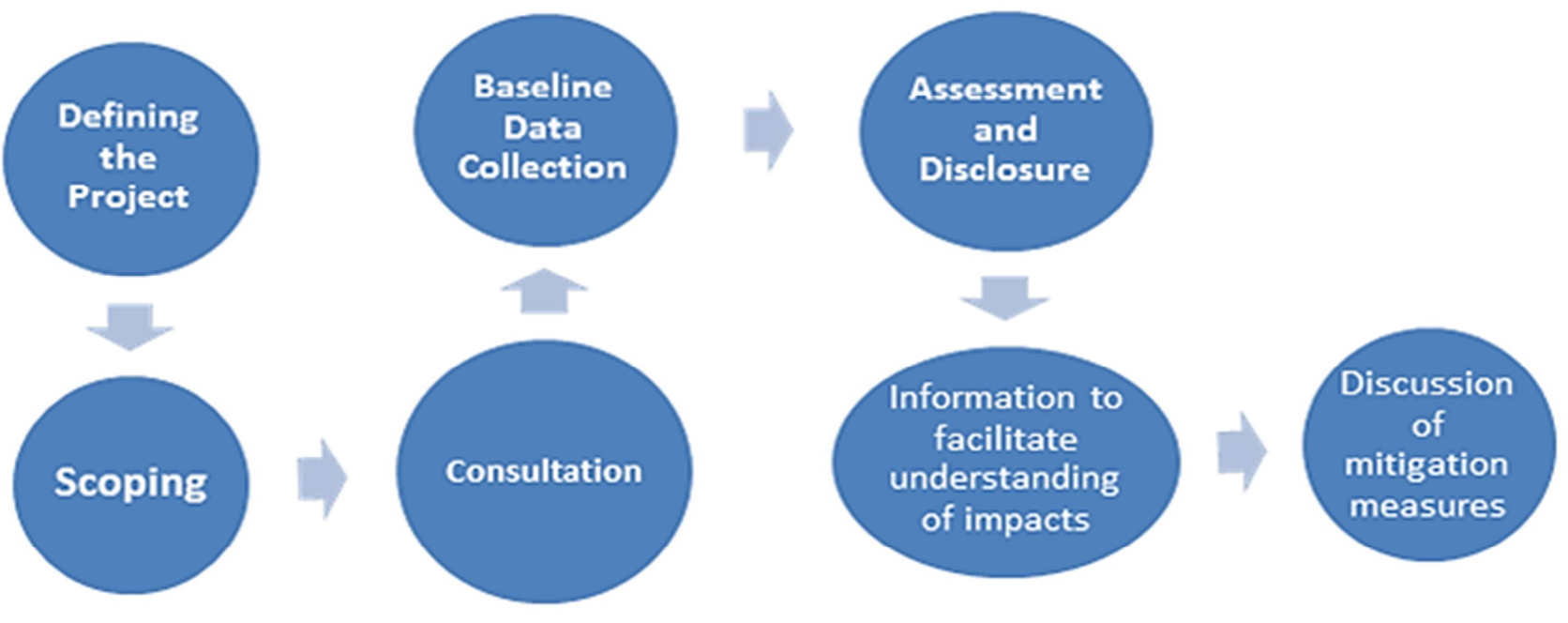

Figure 1. Stages of ESIA.

Whilst this ESIA report presents the findings and recommendations of the ESIA process up to and including the disclosure period, the inclusion of environmental and social considerations into the implementation phases of the proposed Project will be an ongoing and dynamic management activity. A key vehicle for the delivery of environmental management scrutiny and control is the suite of Management and Monitoring Plans, which comprise an integral part of this ESIA Report.

The Management and Monitoring plans present the technical basis for development and implementation of a focused Environmental Management System to manage all relevant activities during construction and operation of the project. As such, the Management and Monitoring plans will evolve and be further developed as implementation of the pipeline and its associated facilities progresses further.

The development of ESIA is made up of the following steps:

- Considering alternatives during the planning and design development of the Pipeline route, the Above Ground Installations (AGIs) and Marine Terminal, the existence of a marine terminal is considered.

- Outlining the methodology that has been adopted in undertaking the ESIA including scoping, consultation, interactions with detailed design, baseline data collection and impact prediction. It also presents the criteria used for assessing significance.

- Presenting a detailed description of the pipeline, its associated Above Ground Installations (AGIs) and marine terminal.

- Presenting the environmental and socio-economic baseline along the pipeline route.

- Describing generic impacts and mitigation along the pipeline anticipated during the Construction Phase.

- Describing identified impacts and mitigation measures associated with normal operation of the pipeline and it is associated Above Ground Installations (AGIs).
- Presenting an environmental risk assessment of possible accidental events arising from operation of the pipeline and its associated Above Ground Installations.(AGIs)

- Presenting a detailed description of the facilities to be incorporated within the Marine Terminal including the terrestrial and marine environmental and socioeconomic baseline for the Marine Terminal.

- Describing the identified marine impacts and mitigation measures associated with construction and operation of the Marine Terminal

- Summarizing the residual impacts that are predicted to occur following the implementation of recommended mitigation measures and potential interactions with other planned developments and resultant cumulative impacts.

- Presenting an overview of how identified environmental and socialissues will be managed during Project construction and operation.

- Presenting the key conclusions of the ESIA Process.

The extent feasible, common impact identification and assessment methodology has been applied through the pipeline. Nevertheless, there are differences in the presentation of information, which reflect differences in the facilities planned and differences in environment sensitivities within the territorial boundaries of each country.

\section{Basis for the Assessment}

This section presents identification of environmental and social impact associated with construction of the Pipeline. It assesses the significance of the identified effect in light of mitigation measures incorporated into design and management of the Pipeline. This section is organized on an environmental and social aspect basis. For each aspect, the section:

- identifies and describes the generic potential impacts that might arise as a result of pipeline construction; 
- describes, where appropriate, the general mitigation measures that have been incorporated into the Project to address potential impacts for that aspect. Any residual impacts are identified.

The identification of potential impact starts at the scoping stage for the ESIA. Initial activities involve the systematic identification of the activities envisaged for all project phases and the environmental and socio-economic resources and receptors along the route, and how the two (project and environment) might interact. Initially, identification is based on a combination of professional judgment and past experience of pipeline projects. Scoping is facilitated by site visits and surveys and initial consultation, particularly with regulatory authorities.

Following a reasonable long of disclosure period (most likely 60 days), the main issues raised are reviewed and addressed where appropriate in the ESIA and management plans. The summary provides an explanation of feedback about the project itself, on social and environmental issues, monitoring and implementation and investment programmes.

As outlined above, consultation is an ongoing process that does not stop once the ESIA report has been submitted for approval determination. Rather, it continues to be an integral part of the process of design, development and implementation of the Project, of which the ESIA itself is just one component.

Scoping is the process for identifying the range of issues, management concerns, preliminary alternatives, and other components of an environmental impact statement; it involves both internal and public viewpoints. Scoping is a critical factor in the start of the ESIA process and in shaping it and determines some or all of the matters to be addressed in the ESIA, including, but not limited to:

- Identifying the impacts or effects to be assessed, especially focusing on those that are critical to decisionmaking by the project proponents, stakeholders and regulatory authorities;

- Assessing the different alternatives to be examined including routes, siting, design solutions and mitigation; and

- Baseline aspects that require particular attention.

Since scoping is a parallel activity running alongside the Basic Engineering phase, it influences route development leading to definition of the $500 \mathrm{~m}$ wide 'Preferred Route Corridor'. Scoping also identifies those aspects of the environment that requiring further detailed study during the full ESIA implementation, and initiates and assists in the impact identification process.

The scoping exercise involves extensive desk studies supplemented by focused field surveys, preparation of constraints maps, stakeholder identification, consultation with government regulators and provincial officials, interaction with the Basic Engineering design teams (especially on routing issues and examining alternatives), identification of potential impacts and key issues for the full ESIA and identification of information gaps and key issues of uncertainty that need to be addressed during the ESIA process.

Although the above description of the scoping process has, by necessity, been described as a discrete step in the ESIA process, in application phases scoping is actually an ongoing and iterative activity. The use of scoping as a dynamic and evolving tool enables the ESIA process to respond to new information, changed emphasis, or project modification arising from the baseline data collection, consultation and design processes.

The assessment of impacts (identify, predict, evaluate, mitigate) is presented as a sequential set of activities; however in practice, it tends to be a dynamic and iterative process. As previously stated impact identification starts in scoping but spans throughout the ESIA process; as new information is obtained during the development of design and as consultation proceeds.

Impact identification also initiates the predictionevaluation-mitigation sequence. However, the outcome at the end of this sequence may be a residual impact following mitigation that is viewed as either unacceptable or where there is room for improvement. Further mitigation is then examined or alternative design or locational solutions are developed. In some occasions therefore, the sequence can be applied in an iterative or cyclic manner until a satisfactory outcome is achieved, rather than as a single thread sequence.

For each potential source of impact identified, a prediction - evaluation - mitigation sequence needs to be applied. For social aspects, stakeholder consultation plays a critical role in determining impact significance. These considerations are carried over into the evaluation of environmental and social impacts.

For a particular environmental aspect for which quantification is possible, the significance criteria are determined by;

(a) the extent to which predicted impacts could be quantified and

(b) the extent to which a quantified limit, standard or guideline exists.

Where both (a) and (b) could be applied the significance criteria are linked to a numerical value (sometimes with caveats) that represented the limit, standard or guideline. Operational discharges to noise and atmosphere are examples of this type of aspect/significance criteria.

For accidental events, a similar approach is adopted in terms of looking at environmental sensitivity and severity of consequence, but the additional dimension of the probability or likelihood of the event occurring is also considered.

The evaluation of social issues and their impacts is not an exact science and requires a considerable degree of subjective judgement. The survey data that has been collected and consultation carried out provides evidence and support for impact evaluation, but does not allow effects to be fully quantified, or their significance to be assessed or ranked numerically. The following methodology and assessment should be read with this in mind.

For each characteristic of the settlement (demographics and migration, land use etc), the types of socio-economic 
effects that could be caused by the project are identified. In evaluating those effects, the following factors are taken into consideration for both the pipeline and marine terminal:

- the likelihood of the effect;

- the duration of this change: short-term disturbance (e.g. during construction only), long term (e.g. during operation period) or permanent;

- the manageability of the change and potential for it to lead to further changes beyond the control of the project;

- the ability of the affected people to adapt to changes and thus maintain livelihoods over the long term.

Significance of the 'residual' effects, which, in the judgement of the ESIA team, will remain as a factor after the mitigation measures have been applied.

The remainder of this Section describes potential impacts, mitigation measures, assessment methods and significance criteria for. [11] and [12],

- Soil

- Groundwater resources

- Landscape and visual impacts]

- Ecology and air quality

- Surface water resources

- Noise Pollution

- Traffic and transport

- Archaeology and cultural heritage

- Social Issues

- The significance of effects on soils has been evaluated using professional judgment and recognized soils science techniques, taking into account of the following factors:

- the magnitude of the effect, as determined by its intensity, its extent in space and time, and the likelihood of its occurrence,

- the vulnerability of the soil to the change caused by the effect,

- the ability of the soil to recover from the effect.

It should be noted that the assessment relates to those areas of soil that will not be covered by permanent facilities (i.e. AGIs and the marine terminal) but focuses on soils that will be disturbed and then subsequently reinstated. The significance of effects on soil resources lost to permanent structures is primarily in terms of effects on ecology and land use and is addressed in the relevant specialized sections.

Landscape and visual effects, though closely related are fundamentally different in nature. Landscape effects are those that arise from the change in character of an area, either by introduction of new elements or changes to existing ones. The receptors of landscape effects are thus ambient features, and a distinction is made between the various project components that affect different landscapes; visual impacts, [13] and [14]. Visual impacts are changes in the view from a defined viewpoint. The receptors of visual impacts are therefore specific groups of people at specific locations, and the impact of the terminal development as a whole has been considered rather than the impact of separate project components.

Potential landscape and visual impacts will result from:
- Changes to the physical structure and elements of the landscape, with possible effects on the wider character of the landscape;

- Impacts on the visual amenity of people.

The significance of any potential impact on surface water quality will depend on the present (or designated) use of the resource (e.g. for drinking supply, fishing, bathing) or its importance to ecology or amenity and the nature and magnitude of change caused by the Project.

For each potential source of impact identified, a prediction or evaluation; mitigation sequence is applied. Prediction takes into consideration any mitigation already inherent in the project design. Prediction methods vary substantially from one environmental or social aspect to another. For some, such as noise pollution and air quality, predicted impacts are quantifiable through accepted methods of calculation or modelling, [15].

For accidental events, a similar approach is adopted in terms of looking at environmental sensitivity and severity of consequence, but the additional dimension of the probability or likelihood of the event occurring is also considered.

The evaluation of social issues and their impact is not an exact science and requires a considerable degree of subjective judgement. The survey data that has been collected and consultation carried out provides evidence and support for impact evaluation, but does not allow impacts to be fully quantified, or their significance to be assessed or ranked numerically. The following methodology and assessment should be read with this in mind.

The magnitude of the impact is then viewed from the perspective of those affected, by taking into account the perceived importance of the impact in the eyes of the affected people, regardless of the basis in fact.

The baseline information for each surveyed settlement was listed under headings detailing the socio-economic characteristics on the settlement levels (e.g. demographics, employment, and infrastructure). Information under each of these headings is compared against a checklist of criteria to determine whether site-specific impacts are likely to occur, and thus require additional mitigation measures.

For the marine terminal, an additional factor is taken into consideration in the evaluation of social impacts, namely, the changes to the assets that households depend upon for their livelihoods. Consideration of this factor is part of the livelihoods assessment undertaken for the impacts associated with the marine terminal.

When assessing impacts on livelihoods, a livelihoods assessment is undertaken, [16] and [17]. This takes a holistic approach to social livelihoods and assumes that each person and group of people have a set of 'assets' of various types grouped into one of the categories;

- Natural capital land, water resources, livestock, fisheries, aggregates, environmental quality,

- Human capital numbers, skills, knowledge, ability to work, health, education,

- Physical capital transport, communications, energy, housing, water and sanitation, schools, health facilities, 
- Social capital leadership and representation, access to support networks and non-governmental institutions, tolerance, ability to demand,

- Financial capital incomes, savings and credit, pensions.

Livelihoods will be affected by changes to the total assets available to an individual or group. Where the total remains the same, but the balance between the different types of capital changes, the resulting impact on livelihood will largely depend on the ability of the individual or group to adapt to change. For social impacts it is often necessary to consider the impacts at the household, settlement and project levels.

- Household Level

Different households will often be affected in different ways by the same impact. It is therefore necessary to assess variation in impacts between different households. For example, a poor household dependent upon natural resources over which it has no legal rights may not have access to compensation or may be ill-equipped to use compensation money in an appropriate way.

- Settlement Level

It is useful to assess the impacts at the settlement level in order to develop further specific settlement level mitigation measures where appropriate.

- Project level

It is also necessary to assess impacts at a more macro level in order to enable the project team to assess cumulative impacts caused by the whole project.

For the assessment of socio-economic impacts, a similar approach can be adopted to ranking impact importance: 'Minor', 'Moderate' and 'Major'. This type of ranking highlights to the project and outside stakeholders those impacts that require most consideration. For example, a development in a rural area may result in a small fluctuation in the economy of the area ('Minor'), may gradually alter the economy from a subsistence base to one that is more market driven over a generation ('Moderate'), or may result in a large influx of immigrants that fundamentally alter the economy within a year ('Major').However, when viewed from the perspective of individual households, the ranking becomes more difficult. For example, a temporary increase in the local prices of raw materials in the local economy could reduce the ability of a poor household to maintain their livelihood, resulting in immediate consequences to their wellbeing. In this context it would undermine the significance of the term 'Minor'.

In the consideration of social impacts, this ESIA therefore only refers to two categories of significance compared to the three levels of significance adopted for ranking environmental impacts. An impact will be ranked as either 'Significant' or 'Not Significant.'

Likelihood is not brought into the criteria for significance. Instead, this will be separately assessed because perception of risk (i.e. the likelihood of an impact occurring) is different for each individual, depending on their level of livelihood or quality of life. Thus, for someone who is impoverished, an impact remains significant regardless of whether there is a high or low likelihood of it occurring, as they would be less able to adapt to the impact, in the event that it occurs.

The impact assessment is applied in an iterative way whereby the significance of an impact is evaluated according to a scale of 'Minor', 'Moderate' or 'Major' significance. An impact assessed as 'Minor' requires no further project faction (on the basis that the impact magnitude is sufficiently negligible, or that the receptor is of low sensitivity and/or that adequate controls are already designed in). An impact assessed as 'Major' always requires further project action in terms of the ESIA and design teams exploring measures to avoid it or to minimise/reduce it to an acceptable level; in seeking to mitigate 'Major' impacts the focus is on the effectiveness of available measures rather than on the cost or practicability of measures. For impacts assessed as 'Moderate', the emphasis is slightly different in that the onus is on demonstrating the impact is reduced to a level that is as low as reasonably practicable. This does not necessarily mean that 'Moderate' impacts have to be reduced to 'Minor' ones, and cost of reducing impact versus the benefit of the reduction is a valid factor in making the eventual decision.

Mitigation in the project has been largely applied through a hierarchy whereby:

- a primary objective is to avoid impacts outright, e.g. through routing and siting decisions, or adopting a technology that avoids certain emissions

- if outright avoidance is not possible, then impacts are reduced at source, e.g. through narrowing the right of way or minimizing waste

- where avoidance or reduction at source cannot be achieved, then the impact is abated on site, e.g. through erosion control measures, landscaping and waste management

- where none of the above are practical, impacts are abated at the receptor, e.g. through transplantation of rare flora and fauna or moving beehives away from pipeline construction corridors

- some impacts are completely unavoidable and require 'repair' mechanisms such as reinstatement of the pipeline corridor and decommissioned temporary work sites;

- where none of the above are practical, compensation is applied, e.g. for affected agricultural land users/landowners.

In terms of enhancements, the project will implement a Community Investment Program in order to bring sustainable benefits to settlements most affected by construction activities and an Environmental Investment Program to offset the overall ecological impacts along the route. As previously mentioned, in the iterative process of impact assessment a prime objective is to reduce potentially significant (i.e. 'Moderate' and 'Major' for environmental impacts and simply 'Significant' for social impacts) impacts to acceptable levels.

The mitigation measures used for eliminating or reducing significant (i.e. 'Moderate', 'Major' or 'Significant') impacts have been built into the design and incorporated into 
contractual specifications for the Construction Contractors. This ESIA therefore concludes with an assessment of the significance of the 'residual' impacts. These are the impacts that in the judgement of the ESIA team will remain after the mitigation measures have been applied.

Clearly it is an ideal objective of the ESIA process to move towards a position where there are no significant impacts. This is not always possible since uncertainty is a real and present factor in ESIA, and one way to deal with uncertainty is to be conservative in the assessment. These stem from a degree of uncertainty (e.g. precisely how effective certain reinstatement measures might be in difficult soils, or proximity of residents to noisy construction activity and hence the likely noise pollution exposure levels) combined with a conservative application of the assessment process and criteria. Section 15 therefore also sets out how the project will specifically manage and reduce impacts that are currently perceived as potentially significant.

The potential exists for soil contamination as an effect the project. The Environmental Management and Monitoring Plan (EMMP) make provision for prompt and complete cleanup of any contamination caused during construction. Typically such spills would be small, readily contained and soil would be removed as a waste. No significance criteria are therefore presented.

Landscape and visual impacts, though closely related are fundamentally different in nature. Landscape impacts are those that arise from the change in character of an area, either by introduction of new elements or changes to existing ones. The receptors of landscape impacts are thus ambient features, and a distinction is made between the various project components that affect different landscapes. Visual impacts are changes in the view from a defined viewpoint. The receptors of visual impacts are therefore specific groups of people at specific locations, and the impact of the terminal development as a whole is considered rather than the impact of separate project components.

The significance of any potential impact on surface water quality will depend on the present (or designated) use of the resource (e.g. for drinking supply, fishing, bathing) or its importance to ecology or amenity and the nature and magnitude of change caused by the project.

The Regulation on Control of Water Pollution (RCWP) assigns ambient water quality criteria for receiving water bodies based on established water quality classifications. The four water quality classifications for inland surface waters (i.e. rivers, lakes and reservoirs) are as follows:

- Class I: High quality water

- Class II: Slightly polluted water

- Class III: Polluted water

- Class IV: Extremely polluted water

For crude oil pipelines, an Oil Spill Response Plan (OSRP) must be prepared for contingency planning, determination of contingency equipment and reponse andrisk calculations.For gas pipelines, fire, toxicity, explosion and fire are important factors and contingency planning and risk assessment must beconsideres for mitigation measures.

\section{Conclusion}

Prepaing, mitigating and defining are explained throughout the paper, [18], [19], [20], [21] and [22]. The possible detail information is provided, however local mitigation measures for oil or gas pipelines may not be covered.These cases can be handled by using general principles of ESIA.

The quantitative analyses and case studies are not presented in the the study, since these analyses and data belong to oil industry in most cases. However, the paper provides susfficient information to prepare a succesful ESIA study fora crude and gas pipeline.

\section{References}

[1] C. Barrow, Environmental and Social Impact Assessment, John Wiley, New York, 1997.

[2] N. Harvey and Beverley Clarke, Environmental Impact Assessment: Procedures and Practices, Oxford Uni. Press, 2012.

[3] R. K. Morgan, Environmental Impact Assessment: A Methodological Approach, Kluwer, 2002.

[4] F. Vanclay and A. M. Esteves, New Directions in Social Impact Assessment: Conceptual and Methodological Advances, Edward Elgar Pub., Northampton, Mass., 2012.

[5] A. Woodhouse, Social capital and economic development in regional Australia: A case study, Journal of Rural Studies, (22): 83-94, 2006.

[6] B. Noble, Introduction to Environmental Impact Assessment Guide to Principles and Practice, Don Mills ON: Oxford University Press, 2005.

[7] K. Hanna, Environmental Impact Assessment: Practice and Participation. Don Mills ON: Oxford University Press, 2005.

[8] C. Hua, Energy-related boom towns: problems, causes, policies, and modeling. In Large-Scale Energy Projects: Assessment of Regional Consequences, ed. T R Lakshmanan and B Johansson, pp. 215-232. Amsterdam: Elsevier Science Publishers, 1985.

[9] R. Chambers, Shortcut methods of gathering social information for rural development projects, In Putting People First: sociology and development projects, 1985.

[10] R. Chambers and G. Conway, cited in Drinkwater 1992, Sustainable rural livelihoods: practical concepts for the $21 \mathrm{st}$ century, Institute of Development Studies Discussion Paper 296, Brighton, UK: IDS, 1992

[11] Mohammed K. Hamadina, Dimie Otobotekere and Donald I. Anyanwu, Impact Assessment and Biodiversity Considerations in Nigeria: A Case Study of Niger Delta University Campus Project on Wildlife in Nun River Forest Reserve, 18/2 Manage of Environ Quality: An Int'l Journal 179, 195, 2007.

[12] E. J. Alagoa, The People: Traditions of Origin, in E .J. Alagoa ed., The Land and People of Bayelsa State, Central Niger Delta 73, Port Harcourt: Onyoma Research Publications, 1999. 
[13] Allan Ingelson and Chilenye Nwapi, Environmental Impact Assessment Process for Oil, Gas and Mining Projects in Nigeria: A Critical Analysis, 10/1 Law, Environment and Development Journal, p. 35, available at (http://www.leadjournal.org/content/14035.pdf), 2014.

[14] Surgil Project ESIA - Volume II, ESIA Report - Final Draft, November 2011, Uz-Kor Gas Chemical, 2011.

[15] ESIA/EA GUIDELINES, Environment and Social Impact Assessment and Audit Guidelines for the Downstream Petroleum Sub-sector, Energy Regulatory Commission, June 2012.

[16] Oil and Gas Pipelines Social and Environmental Impact Assessment, State of the Art, Editor Robert Goodland, Robert Goodland, for IAIA 2005 Conference International Association of Impact Assessment, May 2005.

[17] Environmental and Social Impact Assessment (ESIA) Report for the Nairobi Transmission Ring Project, Kenya Power and Lighting Company, Prepared by Kamfor Company Ltd. and Elaine Tyldesley, May 2011.
[18] B. Noble, B. and K. Storey, Towards increasing the utility of follow-up in Canadian EIA, Environmental Impact Assessment Review, 25(2): 163-180, 2005.

[19] Environmental and Social Impact Assessment (ESIA) Report for the Nairobi Transmission Ring Project, Kenya Power and Lighting Company, Prepared by Kamfor Company Ltd. and Elaine Tyldesley, May 2011.

[20] B. Noble, Auditing strategic environmental assessment practice in Canada, Journal of Environmental Assessment Policyand Management, 5: 127-147, 2003.

[21] A. Morrison-Saunders, R. Marshall and J. Arts, EIA Followup International Best Practice Principles. Special Publications Series No.6, International Association for Impact Assessment, Fargo, USA, 2007.

[22] A. Morrison-Saunders, B. Jenkins and J. Bailey, EIA followup and adaptive management, in: A. Morrison-Saunders, A. and J. Arts J. (eds.) Assessing Impact: Handbook of EIA and SEA Follow-up, Earthscan, London, pp. 154-177, 2004. 